\title{
Analisis Produktivitas Tenaga Kerja Pemasangan Ubin Keramik Pada Proyek Makassar New Port
}

\author{
Acen Patanduk ${ }^{1}$, Josefine Ernestine Latupeirissa ${ }^{2}$, Herby Calvin Pascal Tiyouw ${ }^{3}$ \\ *1 Mahasiswa program studi teknik sipil di Universitas Kristen Paulus Indonesia Makassar, Indonesia \\ acenpatanduk97@gmail.com \\ *2 Dosen program studi teknik sipil Universitas Kristen Paulus Indonesia, Makassar, Indonesia \\ josefine ernestine@yahoo.com \\ *3 Dosen program studi teknik sipil Universitas Kristen Paulus Indonesia, Makassar, Indonesia \\ herbycalvin@ukipaulus.ac.id
}

\begin{abstract}
ABSTRAK
Penelitian ini bertujuan untuk mengetahui kapasitas produktivitas tenaga kerja pemasangan ubin keramik proyek Makassar New Port, berdasarkan data lapangan dan Standar Nasional Indonesia (SNI). Penelitian ini dikerjakan selama \pm 10 hari pada proyek Makassar New Port dengan tukang yang bekerja pada pekerjaan pemasangan ubin keramik menjadi objek yang diteliti sebagai sumber data dalam penelitian ini, dan setaip faktor-faktor yang berdampak pada kinerja sumberdaya manusia di lapangan khususnya mengenai kecepatan, keahlian dan ketepatan kerja. Pemasangan ubin keramik diamati per meter persegi dalam satu hari kerja dan setiap data dicatat selama penelitian berlangsug. Work study adalah metode yang menjadi pilihan untuk dignakan dalam penelitin ini. Pengamatan dilakkukan dengan menghimpun data primer yang diteliti langsung di lapangan dan data sekunder berupa gambar setiap lantai bangunan yang diteliti. Disebut sebagai metode work study karena data pengamatan diambil pada saat sedang mengadakan pekerjaan dilapangan. Hasil dari penelitian ini adalah kapasitas produksi pada pekerjaan pasangan ubin keramik pada proyek Makassar New Port lebih besar dibandingkan dengan Standar Nasional Indonesia (SNI), ini menunjukkan bahwa tenaga kerja yang di gunakan pada pekerjaan pasangan batu penahan tanah sangat produktif.
\end{abstract}

Kata kunci: Kapasitas produksi tenaga kerja, Standar Nasional Indonesia (SNI)

\begin{abstract}
The aim of this study is to investigate the productivity capacity of the ceramic tile installation workforce at the Makassar New Port project, based on field data and the Indonesian National Standard (SNI). This research was conducted for \pm 10 days in the Makassar New Port project. The objects to be studied as a source of data in this research are workmen who work on ceramic tile installation, regarding the factors that affect the performance of human resources in the field, especially on their work skills, speed, and accuracy. The observations were made per square meter of ceramic tile installation for each work item on 1 working day, while data recording was carried out per day for 6 working days. The research method used in this research is the work study method, which is a research conducted by collecting data directly from observations in the field. This research was conducted by collecting primary data which is directly examined in the field related to the research carried out as secondary data, which is called the work study method because the observational data is taken while conducting the field work. The result of this research is that the production capacity in the ceramic tile installation of the Makassar New Port project is bigger than the Indonesian National Standard (SNI), this shows that the hired workmen in the work of the retaining stone installation work is very productive.
\end{abstract}

Keywords: Workmen production capacity, Indonesian National Standard (SNI)

\section{PENDAHULUAN}

Produktivitas merupakan perbandingan antara input dan output, dimana input dinyatakan sebagai orang-hari $(\mathrm{O} \mathrm{H})$ atau orang-jam $(\mathrm{O} \mathrm{J})$, sedangkan output dinyatakan sebagai hasil pekerjaan (berupa kuantitas) dengan variasi satuan yang tergantung pada jenis pekerjaan yang dianalisis [1].

Pada kegiatan proyek konstruksi, perencanaan digunakan sebagai acuan dan standar dalam melaksakan pekerjaan [2]. Perkembangan konstruksi di kota Makassar terlihat berkembang pesat dengan peningkatan pembangunan baik berupa gedung-gedung atau sarana transportasi seperti jalan layang dan pelabuhan. Pada pekerjaan proyek konstruksi tersebut kemungkinan terjadinya kondisi ketidakpastian mengakibatkan durasi pelaksanaan pekerjaan menjadi bertambah, sehingga proyek tersebut terlambat diselesaikan.

Salah satu yang menyebabkan terlambatnya penyelesaian proyek antara lain karena rendahnya 
Paulus Civil Engineering Journal

Jurnal Teknik Sipil UKI-Paulus Makassar

https://doi.org/10.52722/pcej.v3i2.3202

produktivitas dimiliki oleh tenaga kerja di Indonesia sehingga perlu lagi untuk ditingkatkan [3]. Kegiatan operasional PT.Pelindo IV (Persero) pada dasarnya meliputi arus kapal, arus peti kemas, arus penumpang, dan arus barang. Arus bongkar muat meningkat terus menerus setiap tahunnya dengan demikian sejalan dengan perkembangan volume kegiatan operasional yang ditangani oleh Terminal Petikemas PT. Pelindo IV (Persero) maka dipandang bahwa ketersediaan fasilitas bongkar muat peti kemas sangat terbatas dan sudah tidak memadai, sehingga perlu dilakukan penambahan fasilitas untuk mampu mengantisipasi pertumbuhan lintasan petikemas di masa mendatang.

Dalam penerapannya maka PT.Pelindo IV (Persero) melakukan penambahan fasilitas yaitu membangun Terminal Petikemas Makassar (TPM) yang disebut dengan proyek Makassar New Port (MNP). Salah satu bangunan penunjang bangunan terminal adalah Gedung Operasional dan dalam proses pembangunannya terdapat pekerjaan pemasangan ubin marmer pada tiap lantainya.

Pekerjaan pasangan ubin yang akan dilakukkan menggunakan material ubin teralux marmer atau keramik berukuran $60 \times 60 \mathrm{~cm}$. Untuk melakukan pekerjaan tersebut dibutuhkan tenaga kerja yang cukup banyak. Dengan adanya tenaga kerja yang cukup banyak tentu saja akan mengeluarkan biaya yang besar untuk upah kerja. Oleh karena itu tenaga kerja yang ada harus menghasilkan volume pekerjaan yang sama atau lebih tinggi dari standar yang ditentukan. Cara untuk melihat hasil kerja para pekerja atau produktivitas adalah dengan membandingkan hasil kerja dengan standar yang digunakan yaitu Standar Nasional Indonesia (SNI). Sumber daya manusia dapat dikatakan produktif apabila memiliki produktivitas kerja yang tinggi sehingga pekerjaan dapat diselesaikan tepat waktu [4].

Berdasarkan uraian di atas maka peneliti tertarik melakukan analisis mengenai produktivitas tenaga kerja pemasangan ubin keramik pada proyek Makassar New Port berdasarkan data lapangan dan Standar Nasional Indonesia (SNI).

\section{METODE}

\section{Gambaran Umum dan Lokasi Proyek}

Volume 3 No.2, Juni 2021

e-ISSN 2775-4529

p-ISSN $2775-8613$
Tempat penelitian ini adalah proyek Makassar New Port Paket $\mathrm{D}$ dengan gambaran umum proyek tersebut yaitu, pembangunan Fasilitas Mekanikal dan Elektrikal dalam paket D Makassar New Port.

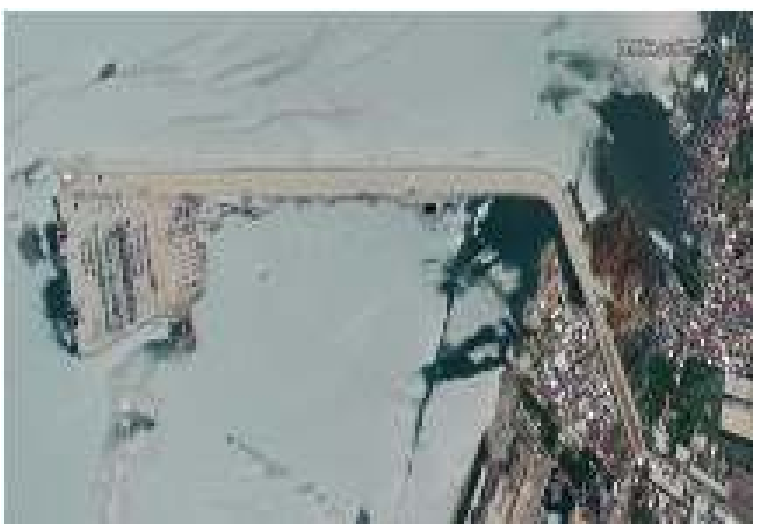

Gambar 1. Peta lokasi penelitian

Penelitian ini dilakukan pada tanggal 18 November 2019 sampai 28 November 2019 pada proyek Makassar New Port, yang berada di Jl. Abdullah Raya, Kaluku bodoa, Kec.Tallo, Kota Makassar. Dengan PT Pelindo IV sebagai owner, PT Virama Karya sebagai konsultan dan PT Adhi Karya sebagai kontraktor. dan tukang yang bekerja pada pemasangan ubin keramik menjadi sumber data dalam penelitian ini. Pengamatan dilakukan pada masing-masing item pekerjaan selama 10 hari kerja, dan berada pada lantai satu dan lantai dua.

\section{Pengumpulan Data}

Penelitian ini dimulai dengan mengumpulkan data kapasitas produktivitas tenaga kerja berupa data primer dan sekunder.

\section{a. Data primer}

Data primer didapatkan dengan metode pengukuran secara langsung menggunakan alat ukur meter, yang kemudian dicatat sehingga mendapatkan luas rata-rata hasil kerja tukang perharinya.

Data :

$\begin{array}{ll}\text { Panjang } & =50,400 \mathrm{~m} \\ \text { Lebar } & =18,500 \mathrm{~m}\end{array}$

Luas area kerja lantai $1=1031,328 \mathrm{~m}^{2}$

Luas area kerja lantai $2=863,128 \mathrm{~m}^{2}$

Luas total area kerja $\quad=1894.456 \mathrm{~m}^{2}$

Tabel 1.Data produksi pemasangan ubin keramik lantai 2

\begin{tabular}{ccc}
\hline Hari & $\begin{array}{c}\text { Jumlah Tukang }+ \\
\text { Jumlah Buruh }\end{array}$ & Produksi (Tukang $/ \mathrm{m}^{2} /$ hari) \\
\hline
\end{tabular}




\begin{tabular}{ccc}
\hline & (orang) & \\
\hline Senin 18.11.2019 & $10+10$ & 8.8836 \\
Selasa 19.11.2019 & $10+10$ & 8.8060 \\
Rabu 20.11.2019 & $10+10$ & 8.9072 \\
Kamis 21.11.2019 & $10+10$ & 8.6846 \\
Jumat 22.11.2019 & $10+10$ & 8.5024 \\
Sabtu 23.11.2019 & $10+10$ & 8.4624 \\
Senin 25.11.2019 & $10+10$ & 8.7018 \\
Selasa 26.11.2019 & $10+10$ & 8.7924 \\
Rabu 27.11.2019 & $10+10$ & 8.6112 \\
Kamis 28.11.2019 & $10+10$ & 8.9612 \\
\hline \multicolumn{2}{l}{ Rata-rata produksi } & 8.7313 \\
\hline
\end{tabular}

Tabel 2. Data produksi pemasangan ubin keramik lantai 1

\begin{tabular}{ccc}
\hline Hari & $\begin{array}{c}\text { Jumlah Tukang }+ \text { Jumlah Buruh } \\
\text { (orang) }\end{array}$ & Produksi (Tukang $/ \mathrm{m}^{2} /$ hari) \\
\hline Senin 02.12.2019 & $10+10$ & 10.3836 \\
Selasa 03.12.2019 & $10+10$ & 10.3060 \\
Rabu 04.12.2019 & $10+10$ & 10.3072 \\
Kamis 05.12.2019 & $10+10$ & 10.4046 \\
Jumat 06.12.2019 & $10+10$ & 10.5024 \\
Sabtu 07.12.2019 & $10+10$ & 10.2916 \\
Senin 10.12.2019 & $10+10$ & 10.3018 \\
Selasa 11.12.2019 & $10+10$ & 10.3924 \\
Rabu 12.12.2019 & $10+10$ & 10.6112 \\
Kamis 13.12.2019 & $10+10$ & 10.6612 \\
\hline \multicolumn{2}{c}{ Rata-rata produksi } & 10.4162 \\
\hline
\end{tabular}

b. Data sekunder :

Dalam penelitian ini data sekunder diperoleh dari penelitian gambar kerja dan jumlah tenaga kerja yang digunakan. Maka didapatkan produktivitas para pekerja. Apabila lebih kecil maka akan di evaluasi mungkinkah di tambah waktu kerja atau menambah jumlah pekerja.

(a)

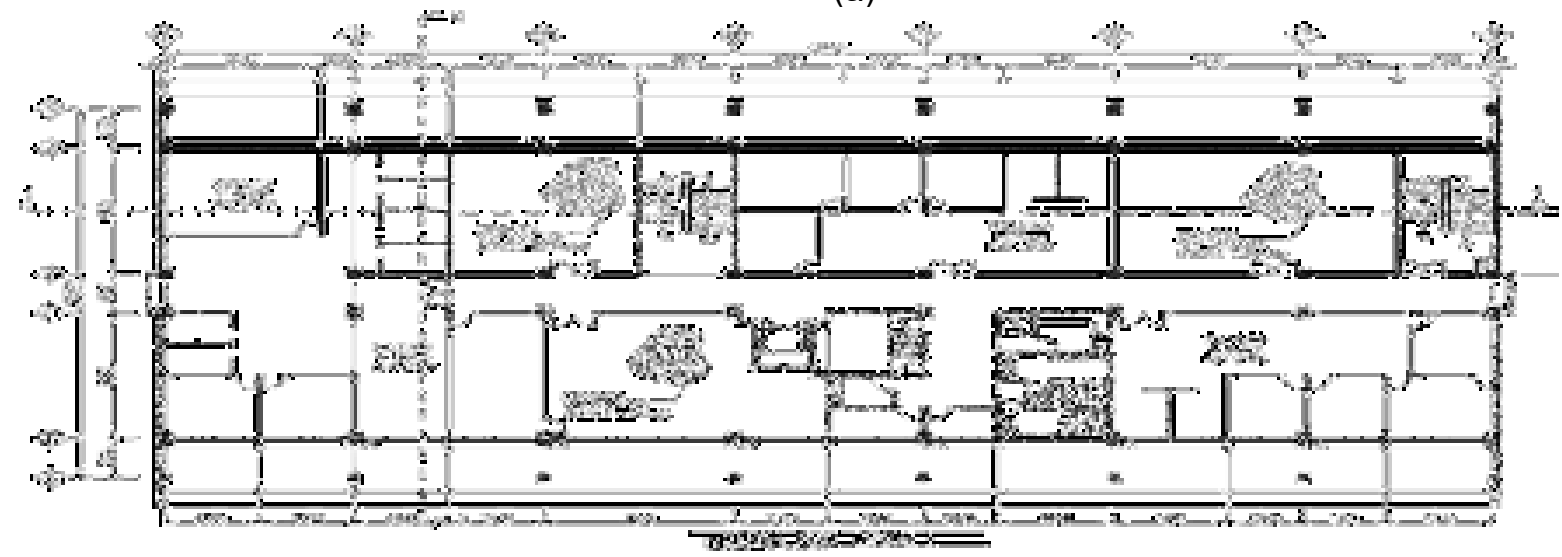

(b)

Gambar 2. Rencana Denah proyek, (a). Lantai 2 dan (b). lantai 1

\section{Pengolahan Data}

Data primer dan sekunder yang terkumpul kemudian dianalisis berdasarkan Standar Nasional Indonesia (SNI).
HASIL DAN PEMBAHASAN

\section{Produktivitas Tenaga Kerja Lantai 1 dan 2}

Berikut merupakan tabel produktivitas perhari dengan produktivitas rata-rata.

Tabel 3. Produktivitas pemasangan ubin keramik (a). Lantai 2 dan (b). Lantai 1 


\begin{tabular}{cc}
\hline Tanggal & $\begin{array}{c}\text { Produksi Tukang } \\
\left(\text { Orang } / \mathrm{m}^{2} / \text { hari) }\right.\end{array}$ \\
\hline $02 / 12 / 2019$ & 8.8836 \\
$03 / 12 / 2019$ & 8.8060 \\
$04 / 12 / 2019$ & 8.9072 \\
$05 / 12 / 2019$ & 8.6846 \\
$06 / 12 / 2019$ & 8.5024 \\
$07 / 12 / 2019$ & 8.4624 \\
$09 / 12 / 2019$ & 8.7018 \\
$10 / 12 / 2019$ & 8.7924 \\
$11 / 12 / 2019$ & 8.6112 \\
$12 / 12 / 2019$ & 8.9612 \\
\hline Rata-rata prduksi & 8.7313 \\
\hline
\end{tabular}

\begin{tabular}{cc}
\hline Tanggal & Produksi $\left(\right.$ Tukang $/ \mathrm{m}^{2} /$ hari $)$ \\
\hline $02 / 12 / 2019$ & 10.3836 \\
$03 / 12 / 2019$ & 10.3060 \\
$04 / 12 / 2019$ & 10.3072 \\
$05 / 12 / 2019$ & 10.4046 \\
$06 / 12 / 2019$ & 10.5024 \\
$07 / 12 / 2019$ & 10.2916 \\
$10 / 12 / 2019$ & 10.3018 \\
$11 / 12 / 2019$ & 10.3924 \\
$12 / 12 / 2019$ & 10.6112 \\
$13 / 12 / 2019$ & 10.6612 \\
\hline Rata-rata prduksi & 10.4162 \\
\hline
\end{tabular}

(b)

Hubungan antara produktivitas perhari dengan produktivitas rata-rata pada pekerjaaan pemasangan ubin keramik pada lantai 2 dan lantai 1 digambarkan sebagai berikut.

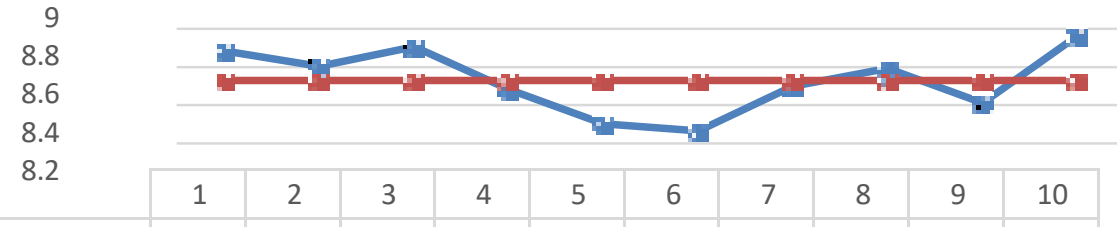

Produkduksi per hari $8.8836 \quad 8.806 \quad 8.90728 .68468 .50248 .46248 .70188 .79248 .61128 .9612$

Produksi rata-rata $\quad 8.73138 .73138 .73138 .73138 .73138 .73138 .73138 .73138 .73138 .7313$

Produkduksi per hari rata-rata

(a)

Hubungan Produksi Perhari dengan produksi rata-rata pemasangan ubin keramik lantai 1

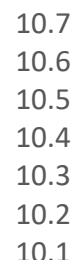

10.6

10.5

10.4

10.3

10.2

10.1

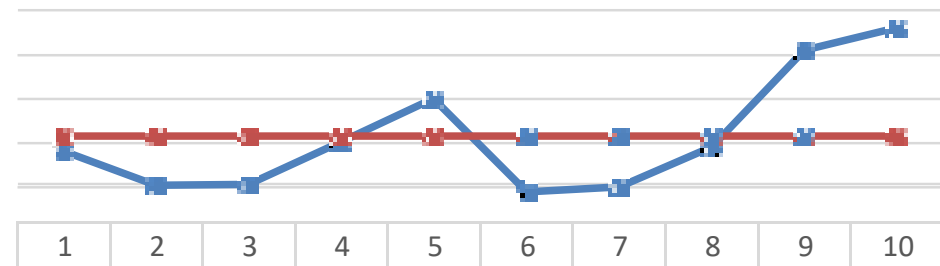

Produkduksi per hari 10.383€10.30610.307210.404610.502410.291610.301810.392410.6112:0.661

Produksi rata-rata $\quad 10.41610 .41610 .41610 .41610 .41610 .41610 .41610 .41610 .41610 .416$ 
(b)

Gambar 3. Grafik hubungan produksi perhari dengan produksi rata-rata pada pekerjaan pemasangan ubin keramik (a). Lantai 2 dan (b). Lantai 1.

\section{Pekerjaan Pemasangan Ubin Keramik lantai 2 dan lantai 1}

Tabel 4. Komposisi tenaga kerja pasangan ubin keramik di lantai 2

\begin{tabular}{ccc}
\hline Nama Mandor & Jumlah Tenaga Kerja/Hari & $\begin{array}{l}\text { Perbandingan } \\
\text { Pekerja/Buruh }\end{array}$ \\
\hline Sukarman & 10 Pekerja +10 Buruh & $1: 1$ \\
\hline$k=\frac{1}{f}\left(\frac{\text { volume }}{\text { hari-orang }}\right)$ & 1 & Indeks produktivitas
\end{tabular}

Dengan : $f=0,120 \mathrm{O} \cdot \mathrm{H}$ (standar produksi tukang pada $\mathrm{SNI}$ [6]

jadi $\quad: k=\frac{1}{0,120}=8,324 \mathrm{~m}^{2} /$ hari-orang

Indeks produktivitas $=\frac{8,333}{8,7313}=0,954$

Berdasarkan SNI didapatkan 8,333 $\mathrm{m}^{2} / \mathrm{hari}$, sedangkan hasil produksi yang dianalisa yaitu $8,7313 \mathrm{~m}^{2} /$ hari. Hasil ini menunjukkan bahwa analisis produksi tenaga kerja yang diteliti lebih besar dibandingkan dengan produksi tenaga kerja standar. Ini menunjukkan bahwa tenaga kerja yang digunakan pada pekerjaan pasangan ubin keramik baik digunakan, dengan indeks produktivitas dihitung sebagai berikut [7]:

Keterangan:

KP : Kapasitas Produksi

Indeks produktivitas $=0,954<1$, ini memperlihatkan tenaga kerja konstruksi mengalami peningkatan produktivitas. Hasil penelitian dibandingkan dengan kondisi standar dengan persentase peningkatan produktivitas sebagai berikut.

$$
\begin{aligned}
\% \text { peningkatan } & =\left(\frac{8,7313-8,333}{8,333} \times 100 \%\right) \\
& =4,573 \%
\end{aligned}
$$

Tabel 5. Komposisi tenaga kerja pasangan ubin keramik di lantai 1

\begin{tabular}{ccc}
\hline Nama Mandor & Jumlah Tenaga Kerja/Hari & $\begin{array}{l}\text { Perbandingan } \\
\text { Pekerja/Buruh }\end{array}$ \\
\hline Sukarman & 10 Pekerja +10 Buruh & $1: 1$ \\
\hline
\end{tabular}

$k=\frac{1}{f}\left(\frac{\text { volume }}{\text { hari-orang }}\right)$

Dengan : $f=0,120 \mathrm{O} . \mathrm{H}$ (standar produksi pekerja pada $\mathrm{SNI}$ )

jadi $\quad: k=\frac{1}{0,120}=8,333 \mathrm{~m}^{2} /$ hari-orang

Berdasarkan SNI didapatkan $8,333 \mathrm{~m}^{2} / \mathrm{hari}$, sedangkan hasil produksi yang dianalisa yaitu 10,4162 $\mathrm{m}^{2} /$ hari. Hasil ini menunjukkan bahwa analisis produksi tenaga kerja yang diteliti lebih besar dibandingkan dengan produksi tenaga kerja standar. Ini menunjukkan bahwa tenaga kerja yang digunakan pada pekerjaan pasangan ubin keramik baik digunakan, dengan indeks produktivitas dihitung sebagai berikut:

Indeks produktivitas $=\frac{\text { KP kondisi standar }}{\text { KP kondisi lapangan }}$
Indeks produktivitas $=\frac{8,333}{10,4162}=0,800$

Indeks produktivitas $=0,800<1$, ini memperlihatkan tenaga kerja konstruksi mengalami peningkatan produktivitas. Hasil penelitian dibandingkan dengan kondisi standar dengan persentase peningkatan produktivitas sebagai berikut.

$$
\begin{aligned}
\% \text { peningkatan } & =\left(\frac{10,4162-8,333}{8,333} \times 100 \%\right) \\
& =24,999 \%
\end{aligned}
$$

Komposisi Tenaga Kerja Pasangan Ubin Keramik Berdasarkan SNI 7395 : 2008 No. 6.13 [6]

$\begin{array}{ll}\text { Pekerja } & =0,240 \mathrm{OH} \\ \text { Tukang } & =0,120 \mathrm{OH} \\ \text { Kepala tukang } & =0,012 \mathrm{OH} \\ \text { Mandor } & =0,012 \mathrm{OH} \\ 1 \text { tukang } & : 1 \text { pekerja }\end{array}$


1 mandor

: 20 pekerja

Berdasarkan hasil analisis maka di dapatkan produktivitas tenaga kerja di lapangan pada pekerjaan pemasangan ubin keramik lebih besar di bandingkan dengan produktivitas berdasarkan Standar Nasional Indonesia (SNI).

Tabel 6. Tabel hasil analisa perhitungan

\begin{tabular}{|c|c|c|c|c|c|}
\hline Lantai & $\begin{array}{l}\text { Hasil Perhitungan } \\
\text { Kapasitas Produksi } \\
\text { (k) }\left(\mathrm{m}^{2} / \text { hari }\right)\end{array}$ & $\begin{array}{c}\text { Standar } \\
\text { Nasional } \\
\text { Indonesia } \\
\text { (SNI) } \\
\text { Kapasitas } \\
\text { Produksi (k) } \\
\text { (m²/hari) }\end{array}$ & $\begin{array}{c}\text { Indeks } \\
\text { Produktivitas }\end{array}$ & $\begin{array}{c}\text { Persentase } \\
\text { Peningkatan } \\
\text { Produktivitas } \\
\text { (\%) }\end{array}$ & Keterangan \\
\hline 1 & 10,4162 & 8,333 & 0,954 & 24,999 & $\begin{array}{c}\text { Indek } \\
\text { produktivitas < } \\
1 \text { kondisi ini } \\
\text { menunjukkan } \\
\text { adanya } \\
\text { peningkatan } \\
\text { produktivitas } \\
\text { tenaga kerja }\end{array}$ \\
\hline
\end{tabular}

\section{KESIMPULAN}

Kesimpulan dari penelitian ini adalah produktivitas pada pekerjaan pemasangan ubin keramik tanah pada proyek Makassar New Port lebih besar dibandingkan dengan Standar Nasional Indonesia (SNI), ini menunjukkan bahwa tenaga kerja yang di gunakan pada pekerjaan pemasangan ubin keramik sangat produktif dan layak untuk digunakan.

\section{UCAPAN TERIMA KASIH}

Puji syukur kehadirat Tuhan Yang Maha Esa oleh karena anugerah dari-Nya, sehingga penyusun dapat menyelesaikan tugas akhir ini dengan baik. Penulis mengucapkan terima kasih yang teramat dalam kepada kedua orang tua yang telah mendidik dan memberi penulis kesempatan untuk menempu pendidikan, serta segala nasehat yang selalu menjadi tuntunan hidup bagi penulis.

\section{DAFTAR PUSTAKA}

[1] K. Basari and R. Yoga Pradipta, 2014, "Analisa Koefisien Produktivitas Tenaga Kerja Pada Pekerjaan Pembesian," J. Karya Tek. Sipil, Volume. 3, Nomor. 4. HIm. 830839.

[2] I. Zulkarnain, F. Agustina, I. Wijaya, and M.
R. Azis, 2018, "Model Penetapan Proyek Konstruksi," pp. 86-98.

[3] T. D. Laksono, 2007, "Produktivitas pada proyek konstruksi," Teodolita, Volume. 8, Nomor. 2, HIm. 11-18.

[4] P. K. Karyawan, 2015. "Data Produktivitas Karyawan PT . Primatexco Indonesia Batang ( unit weaving / pertenunan ) Tahun 2011 s / d 2013," Volume. 4, HIm. 1-14.

[5] Supply Chain Indonesia, "Proyek Pelabuhan Makassar New Port Ditargetkan Selesai 2019," suara.com, 2018. https://supplychainindonesia.com/proyekpelabuhan-makassar-new-port-ditargetkanselesai-2019/ (accessed Aug. 07, 2020).

[6] S. N. Indonesia and B. S. Nasional, 2008. "Tata cara perhitungan harga satuan pekerjaan penutup lantai dan dinding untuk konstruksi bangunan gedung dan perumahan,".

[7] D. Pramestari, 2018. "Penentuan Kriteria Perbaikan Produktivitas Pada Suatu Departemen Kerja Dengan Menggunakan Metode Objective Matrix (OMAX)," IkraithTeknologi, Volume. 2, Nomor. 2, HIm. 9-19. 